\title{
TERRA VERSUS TERRITÓRIO: PENSAR CONFLITOS SOBRE TERRITORIALIDADES QUILOMBOLAS A PARTIR DA REALIDADE KALUNGA
}

\author{
TERRA VERSUS TERRITORY: THINKING CONFLICTS ABOUT \\ QUILOMBOLA'S TERRITORIALITY FROM THE KALUNGA REALITY
}

\author{
Daniel Gonçalves de Oliveira* \\ Maria Cristina Vidotte Blanco Tárrega ${ }^{* *}$
}

\begin{abstract}
Resumo: No contexto de uma agrariedade ampliada, em que se busca superar os limites do direito e do estado fundados no capitalismo, com reflexões socioambientais includentes de comunidades tradicionais, propõe-se no presente artigo, a análise jurídica dos direitos territoriais quilombolas e da questão terra propriedade individual versus espaço comunal, tendo por referência a Comunidade Kalunga. A questão centra-se em manter territorialidades pelo preservar da propriedade comum em desfavor da propriedade privada com titulação individual, problema que aparece no debate em várias comunidades quilombolas. $\mathrm{O}$ texto traz uma reflexão crítica do direito como instrumento de dominação e está estruturado em três partes: síntese histórica da Comunidade Kalunga e da gênese do conflito interno para organizar as posses e estabelecimentos territoriais; legislação acerca dos direitos territoriais quilombolas; análise a partir de categorias teóricas bourdieusianas da reprodução social, da violência simbólica e do direito, e de recortes teóricos de autores brasileiros. A ordem jurídica brasileira, tanto da perspectiva constitucional como da legislação infraconstitucional mostram-se ineficientes para dar conta das questões territoriais quilombolas.
\end{abstract}

Palavras-chave: Comunidade Quilombola Kalunga; Direitos Territoriais Quilombolas; Regularização Fundiária; Territorialidades.

\begin{abstract}
In the context of an expanded agrarian system, which seeks to overcome the limits of the right and the state based on capitalism, with social-environmental reflections that include traditional communities, it is proposed in this article, the legal analysis of territorial rights quilombolas and land ownership individual versus communal space, with reference to the Kalunga Community. The issue focuses on maintaining territoriality by preserving common property in detriment of private ownership with individual titling, a problem that appears in the debate in several quilombola communities. The text brings a critical reflection of law as an instrument of domination and is structured in three parts: historical synthesis of the Kalunga Community and the genesis of the internal conflict to organize the territorial possessions and establishments; quilombola territorial rights legislation; analysis based on theoretical and bourdieusian categories of social reproduction, symbolic violence and law, and theoretical cut-outs of Brazilian authors. The Brazilian legal order, both from the constitutional perspective and from the infraconstitutional legislation, are inefficient to deal with quilombola territorial issues.

\footnotetext{
* Mestrando em Direito Agrário pela Universidade Federal de Goiás. E-mail: advgdaniel@ gmail.com.

** Mestre e Doutora em Direito pela Pontifícia Universidade Católica de São de Paulo - PUC-SP. Professora titular da Faculdade de Direito da Universidade Federal de Goiás - UFG. Bolsista produtividade em pesquisa CNPq. E-mail: mcvidotte@uol.com.br.
} 


\section{Daniel Gonçalves de OLIVEIRA \\ Maria Cristina Vidotte Blanco TÁRREGA}

Key words: Quilombola Community Kalunga; Quilombola Territorial Rights; Land regularization; Territorialities.

\section{INTRODUÇÃO}

No contexto de uma agrariedade ampliada, em que se busca superar os limites do Direito e do Estado fundados no capitalismo, com reflexões socioambientais includentes de comunidades tradicionais, propõe-se no presente artigo, a análise jurídica dos direitos territoriais quilombolas e da questão terra propriedade individual versus espaço comunal, tendo por referência a Comunidade Kalunga, localizada ao norte do Estado de Goiás, nos municípios de Cavalcante, Teresina de Goiás e Monte Alegre. Tratase da maior comunidade quilombola do país, a primeira receber uma titulação individual pelo Estado federado (títulos do IDAGO). A questão discutida está centralizada na manutenção das territorialidades, pela preservação da propriedade comum e aparece no debate da titulação em outras comunidades quilombolas.

O texto, em que se aborda o problema da discussão territorial quilombola por meio de uma reflexão crítica do direito como instrumento de dominação, está estruturado em três partes. Na primeira, faz-se uma síntese histórica da Comunidade Kalunga e da gênese do conflito interno na organização das posses e estabelecimentos territoriais; a segunda parte traz um apanhado cronológico da legislação acerca dos direitos territoriais quilombolas; a terceira parte traz o problema a análise a partir de categorias teóricas bourdieusianas da reprodução social, da violência simbólica e do direito e de recortes teóricos de autores brasileiros.

A ordem jurídica brasileira, tanto da perspectiva constitucional como da legislação infraconstitucional mostram-se ineficientes para dar conta das questões territoriais quilombolas, sobretudo do ponto de vista de sua execução, o que acaba por desaguar em problemas internos nas comunidades. Uma das razões desse problema é a racionalidade capitalista do direito moderno e de apropriação e utilização da terra. $\mathrm{O}$ direito de propriedade da terra e as noções utilitaristas e mercadológicas impostas pelo modelo agrícola hegemônico provocam um choque de realidades para as comunidades tradicionais. A adesão à racionalidade moderna acerca do domínio e da utilização da terra provoca o desprezo do sentido atribuído à reprodução cultural e da forma coletiva de utilização do território.

A noção de território utilizada aqui é tributária do pensamento de Milton 
Terra versus território: pensar conflitos sobre territorialidades quilombolas a partir da realidade Kalunga

Santos (1996), que o considera como espaço usado, pois a atividade de relação humana e não humana com a terra, para a produção da vida, é iminentemente cultural, construída a partir de relações sociais, de significados, de sentidos e de memórias relacionadas ao lugar onde se vive e se sonha.

A percepção teórica relacional de Pierre Bourdieu foi considerada a mais adequada para compreender o direito, dada a abertura que promove. É usada para embasar o debate da dominação no que tange à questão suscitada, contribuindo sobremaneira para a construção teórica e metodológica do texto.

\section{A COMUNIDADE QUILOMBOLA KALUNGA E O SEU TERRITÓRIO}

No estado de Goiás, entre os municípios de Cavalcante, Teresina de Goiás e Monte Alegre de Goiás, encontra-se localizada o maior grupo quilombola do país - a Comunidade Quilombola Kalunga - que tem sua origem no século XVIII, no período de exploração do ouro naquele espaço geopolítico. Às margens do rio Paranã e de seus afluentes foi se desenvolvendo um agrupamento de pessoas originárias do regime escravocrata, que se juntaram em comunidade a fim de se protegerem dos horrores da servidão, durante o período colonial e de expansão das colônias portuguesas até o período pós-independência (DIAS, 2016, p. 25).

Esse grupo apartado da sociedade urbana constituiu-se sobre valores comunitários de solidariedade e de cooperação e - desde os anos cruéis do escravismo até a contemporaneidade vai resistindo ao furor do tempo e do desenvolvimento capitalista no espaço agrário que, vez ou outra, afronta de alguma forma o modo solidário e cooperativo de ser e de viver da Comunidade Kalunga.

A luta pelo reconhecimento do território Kalunga iniciou-se por volta do ano de 1982, tendo como protagonistas as mulheres Kalungas e o trabalho da antropóloga Mari Baiocchi, que, conjuntamente com o Instituto de Desenvolvimento Agrário de Goiás - IDAGO (DIAS, 2016, p. 26), propuseram a mobilização e os estudos para a atribuição dos direitos territoriais, evitando a apropriação indevida por parte de particulares. $\mathrm{O}$ direito foi o instrumento por excelência para se verificar o domínio e a legalidade dos títulos de propriedade ou de posses que incidiam sobre área pertencente aos kalungas.

Em 1991, o Estado de Goiás reconheceu a região do território Kalunga como Sítio Histórico Kalunga e, posteriormente, em 2004, a Comunidade Kalunga foi quilombo certificada pela Fundação Cultural Palmares em 2001. A área reconhecida pela Fundação Palmares como sendo Kalunga mede - aproximadamente - 253 hectares ou $2.530 .000 \mathrm{~m}^{2}$ 
que se estendem pelos três municípios supracitados (ALMEIDA, 2010).

A invisibilidade histórica da Comunidade Kalunga (desde o Brasil- colônia) foi então rompida na década de 80 , com os estudos da antropóloga citada e do extinto IDAGO, realizado por seu presidente Aldo Azevedo, aluno do Programa de Mestrado em Direito Agrário da Universidade Federal de Goiás. Iniciava-se um longo período de estudos que trouxeram luz e voz aos sujeitos dessa comunidade.

Os estudos supracitados desdobraram-se no reconhecimento pelo governo estadual da Comunidade Kalunga. Implementou-se um complexo trabalho de regularização fundiária - que, apesar de expressar a "benevolência" estatal, deu-se de forma precária por desconsiderar o vínculo identitário e coletivo que expressa a relação que os quilombolas mantêm com seu espaço físico.

Dessa forma, o território Kalunga foi incluído e dividido no modelo agrário e fundiário lastreado na propriedade privada, individual, mercadológica, subvertendo-se a lógica do vínculo sócio histórico dos sujeitos com seu território, convertendo-o de um espaço de sentidos e sentimentos em um espaço de possíveis disputas e conflitos.

A regularização fundiária pelo IDAGO, antes mesmo de a Constituição Republicana de 1988 romper o silêncio secular referente aos quilombolas, muda a percepção territorial endógena da Comunidade Kalunga, em decorrência do fracionamento do espaço e da titulação individual das posses, rompendo com a maneira coletiva de utilização do espaço físico na comunidade.

Igualmente, o interromper da regularização fundiária nas transições dos governos goianos e posterior previsão constitucional de alocação de competência da União para as questões quilombolas trouxeram imbricados os conflitos internos na Comunidade Kalunga. Isso tem por causa, sobretudo a titulação individual para parcela do grupo e não para a sua integralidade, e ainda pela crença, por parte da comunidade, de que a melhor forma de titulação é a coletiva. Acrescente-se a isso que uns tantos, contemplados de forma desigual e hoje injusta, desejam deixar seus títulos individuais e ficar livres das cercas da propriedade privada, recuperando a liberdade de utilização integral do território para plantar e criar seus animais.

Há impasses vários decorrentes da atuação estatal por intermédio dos instrumentos do direito (fundados na lógica da propriedade individual), intentando sujeitar o território Kalunga ao velho arcabouço jurídico eurocêntrico monista e à estrutura fundiária patrimonialista/capitalista da contemporaneidade.

Somada a isso, há, dentro dos limites do território, a presença de fazendeiros 
Terra versus território: pensar conflitos sobre territorialidades quilombolas a partir da realidade Kalunga

que resistem à desintrusão promovida pelos órgãos responsáveis pela regularização fundiária, o que acaba por aumentar os conflitos internos, em um claro sinal de anuência ou imobilidade do Estado em solucionar o imbróglio existente na maior comunidade quilombola do país.

A desapropriação e a desintrusão têm problemas, sobretudo orçamentários, entretanto, prevê-se que o INCRA emitirá título de forma coletiva em nome da Associação e indenizará os titulares individuais, mesmo os próprios quilombolas que perderão a propriedade privada em favor da coletiva, podendo permanecer no território. Todavia, o INCRA - órgão criado pelo governo federal no projeto desenvolvimentista e expansionista - deixa claro seu papel de promover a regularização fundiária com a devida titulação coletiva. A intrigante questão que fomenta discussões internas - a divergência entre titulação individual e coletiva - restará à própria Comunidade Kalunga, sobretudo no que se refere à vontade de permanecer com seus títulos individuais.

É recorrente a existência de comunidades quilombolas em que integrantes detenham títulos individuais dentro dos territórios coletivos e que hesitam na eleição do modelo interno de exploração territorial.

O território Kalunga tem uma beleza particular. É cercado por serras e coberto pela vegetação dos cerrados, com rios e cachoeiras. Isso facilitou o isolamento e permitiu o desenvolvimento dessa comunidade com sua forma única de viver e de se relacionar com a terra e com a natureza.

Por outro lado, a vida comunitária empoderada pelas lutas e resistências que compõem a história Kalunga, gera conflitos que hão de ser solucionados em prol do sonho de viver em paz na terra onde descansam os ancestrais e se depositam as sementes de esperança.

\section{O DIREITO DOS QUILOMBOLAS AO TERRITÓRIO: UMA SÍNTESE DOGMÁTICA DA QUESTÃO}

Há quatro ou cinco décadas, os direitos territoriais das comunidades afrodescendentes vêm sendo reconhecidos na América Latina. No Brasil, após um século de silêncio, a Constituição de 1988 abordou a questão quilombola e, nos Atos das Disposições Transitórias, precisamente no artigo 68, estabeleceu que os "remanescentes das comunidades quilombolas" que estivessem ocupando suas terras teriam reconhecida a propriedade definitiva, cabendo ao Estado a emissão dos títulos respectivos. 


\section{Daniel Gonçalves de OLIVEIRA Maria Cristina Vidotte Blanco TÁRREGA}

Ainda na Constituição de 1988, e não menos importante, foi assegurado precisamente nos artigos 215 e 216, numa perspectiva multicultural - os direitos culturais dos povos e comunidades tradicionais, dentre eles, os das populações afro-brasileiras, assegurando os modos de criar, fazer e viver (art. 216, II, CF/88), estabelecendo a desapropriação como instrumento adequado ao Poder Público para proteger o patrimônio cultural brasileiro, manifesto em sua sociodiversidade (art. 216, § 2o, CF/88).

Ressalvadas as críticas à forma como a Constituição tratou do direito dos quilombolas, há de se considerar que o artigo 68 do ADCT representou um importante divisor de águas para a questão, pois, pela primeira vez na história, o Estado brasileiro reconheceu a condição de ex-escravos como "proprietários". Nem mesmo a Lei de Liberdade dos Índios (que data do período pombalino) ou a Lei Áurea (que aboliu definitivamente a escravidão negra no Brasil) trouxeram preceitos legais que assegurassem o acesso/permanência à terra aos negros libertos (ALMEIDA, 2008, p. 42).

Acerca de um ano após a promulgação da Constituição de 1988, surge no plano internacional a Convenção n ${ }^{\circ} 169$ da Organização Internacional do Trabalho (OIT), sobre Povos Indígenas e Tribais em Estados Independentes. Esse documento, estruturado em dez partes, dispõe, dentre outros, sobre aspectos econômicos, sociais, culturais e territoriais dos povos e comunidades tradicionais e indígenas, incluindo, nos artigos 13 a 19, disposições específicas sobre o direito ao território. A referida Convenção trouxe novas e positivas perspectivas para os direitos territoriais: ao assegurá-los, potencializase a garantia dos demais direitos como à vida, à identidade, à cultura, por exemplo. Reforça-se assim a ideia de que os povos e as comunidades tradicionais estão intimamente ligados ao território que ocupam, sendo esse espaço essencial para a reprodução material e imaterial da vida.

O direito ao território, resguardado na Convenção 169 da OIT, transcende a ideia de "terra" propriedade privada, ou seja, rompe com a tradição jurídica do bem imóvel apropriável e transacionável, apontando para entendimento segundo o qual o território ocupado por comunidades tradicionais constitui-se como um espaço especial de promoção cultural e de valor identitário a ser garantido e protegido pelos Estados. Todavia, no Brasil, o referido documento só foi incorporado ao ordenamento jurídico pátrio no ano de 2002, por meio do Decreto Legislativo $\mathrm{n}^{\circ} 143$ e, posteriormente, promulgado pelo Decreto 5051/2004 pelo, então presidente, Luiz Inácio Lula da Silva.

No ano de 2003, delinearam-se os procedimentos administrativos para identificação, reconhecimento, delimitação, demarcação e titulação das terras ocupadas 
Terra versus território: pensar conflitos sobre territorialidades quilombolas a partir da realidade Kalunga

pelos quilombolas pelo Decreto n ${ }^{\circ} 4887$. Há neste decreto uma tentativa de definição dos "remanescentes das comunidades dos quilombos", apresentados como "[...] grupos étnico-raciais, segundo critérios de autoatribuição, com trajetória histórica própria, dotados de relações territoriais específicas, com presunção de ancestralidade negra relacionada com a resistência à opressão histórica sofrida” (BRASIL, 2003).

No aspecto territorial, dito Decreto garantiu - ao menos textualmente - o direito de participação dos quilombolas no processo de regularização de seus territórios e estabeleceu que os respectivos títulos seriam emitidos de forma coletiva, pró-indivisa, com cláusulas de impenhorabilidade, inalienabilidade e imprescritibilidade, ponto esse que se mostra extremamente necessário, a fim de manter a utilização coletiva respeitando a cultura de cada comunidade.

Outros dois documentos de cunho administrativo se destacam no que diz respeito à regularização fundiária dos territórios quilombolas. São, respectivamente, de 2007 e 2008: a Portaria nº 98, da Fundação Cultural Palmares; e a Instrução Normativa $\mathrm{n}^{\mathrm{o}}$ 49, do INCRA; ambos dispondo sobre procedimentos a serem adotados quanto à titulação dessas comunidades, com base no Decreto 4887, de 2003. A Fundação Cultural Palmares tem um papel de destaque no processo de auto reconhecimento, cabendo-lhe emitir a certidão de autodefinição como remanescente dos quilombos. A certificação é requisito para que o INCRA realize os demais procedimentos.

Ainda no âmbito infraconstitucional, destaca-se a Lei $\mathrm{n}^{\circ} 12.288$, de 20 de janeiro de 2010, Estatuto da Igualdade Racial, que, em capítulo próprio, trata da questão territorial dos afro-brasileiros, repetindo textualmente, em seu artigo 31, os dizeres do artigo 68 do ADCT.

Outrossim, algumas Constituições estaduais abordaram a questão quilombola, notadamente no que tange à garantia dos direitos territoriais. A Constituição do Estado de Goiás, no Ato das Disposições Constitucionais Transitórias (no artigo 16, referindo-se especificamente à Comunidade Kalunga) repetiu o artigo 68 do ADCT da Constituição Federal e complementou, determinando, por meio de lei complementar, a criação da reserva Kalunga.

A lei complementar referida no $\S 1^{\circ}$ do artigo 16 da ADCT da Constituição do Estado de Goiás, foi elaborada em 1991, e delimitou a área do sítio histórico Kalunga, estabelecendo a exclusividade da propriedade das terras aos descendentes de africanos que integraram o quilombo que ali se formou no século XVIII. Os trabalhos de desintrusão e titulação das terras Kalunga, à época, foram subsidiados pelos estudos da 


\title{
Daniel Gonçalves de OLIVEIRA Maria Cristina Vidotte Blanco TÁRREGA
}

equipe do Projeto Kalunga Povo da Terra, adotados pelo órgão de regularização fundiária do Estado de Goiás (o extinto IDAGO, que foi precursor da titulação das terras Kalunga). A Lei Complementar 11.409/91 foi posteriormente retificada pela Lei Complementar 19/1995.

A partir da análise da Lei Complementar 19/1995, pode-se aferir a potencialidade do conflito fundiário no território Kalunga, especialmente, quando se lê o $\operatorname{artigo} 4^{\mathrm{o}}$ :

\begin{abstract}
Art. $4^{\circ}$ - As glebas de terras compreendidas na área delimitada no parágrafo único do art. 10 que não pertencerem às pessoas mencionadas no art. 2o serão desapropriadas e, em seguida, emitidos os títulos definitivos em favor dos habitantes do sítio histórico com cláusula de inalienabilidade vitalícia, só transferíveis por sucessão hereditária.

Parágrafo único - Quanto às posses, observar-se-á o seguinte:

I - Se estiverem as glebas ocupadas pelas pessoas mencionadas no art. $2^{\circ}$, serão elas regularizadas em favor destas e expedidos os respectivos títulos;

II - As glebas de terras devolutas, ocupadas a qualquer título por pessoas que não se enquadrem na definição do art. 2o, serão arrecadadas e desocupadas, depois de indenizados os seus ocupantes pelas benfeitorias úteis e necessárias (GOIÁS, 1995).
\end{abstract}

A situação do território Kalunga não difere de várias outras comunidades quilombolas do Brasil - é exemplar. Podem-se observar problemas de muitas ordens nas terras kalungas. Dentre eles, há destaque para a apropriação indevida por meio de grilagem e ocupação por não quilombolas, e a falta de recursos financeiros para as indenizações, de tal sorte que, até o presente momento, a regularização fundiária segue em marcha lenta. Não bastassem os problemas acima referidos, há latente na Comunidade Kalunga o conflito interno que se sustenta no contestar da utilização coletiva do território, inculcada sobretudo pelas ações do Estado ou daqueles que intencionam manter o processo de regularização fundiária ao passo que está, ou apropriar-se de áreas adjacentes ou pertencentes aos Kalungas.

Nota-se que o tratamento jurídico e antropológico dispensado a esta comunidade quilombola desconsiderou a dinâmica sociocultural e econômica de exploração territorial que lhe é específica e, também, o potencial de preservação ambiental inerente à forma harmoniosa com que se relaciona com a natureza.

Segundo os últimos dados da Fundação Cultural Palmares, atualizados até a data do dia 25 de abril de 2017, há 2.958 comunidades quilombolas no país, reconhecidas pela Fundação Cultural Palmares, sendo que, desse número, segundo dados do INCRA, tão-somente, 86 títulos foram expedidos às comunidades quilombolas e há 1536 
Terra versus território: pensar conflitos sobre territorialidades quilombolas a partir da realidade Kalunga

processos de titulação de comunidades quilombolas abertos no órgão.

E, se for considerado o ano de 2003, quando entrou em vigor o Decreto 4.887, como marco inicial e as titulações realizadas até o ano de 2015, seriam necessários 970 anos para titular todos os territórios quilombolas até então reconhecidos pela Fundação Cultural Palmares (PRIOSTE, 2016, p. 106).

Desse contexto de regularização fundiária das terras quilombolas, o que se pode auferir é o perene descaso pela questão afrodescendente. Caso exemplar da Comunidade Quilombola Kalunga que, tendo sido a primeira a ser reconhecida pela Fundação Cultural Palmares, ainda não teve seu processo de regularização fundiária concluído, o que acaba por (re)criar e acirrar conflitos externos e internos na comunidade.

Repetindo o poeta Carlos Drummond de Andrade, no poema "Nosso Tempo", "As leis não bastam. Os lírios não nascem da lei. Meu nome é tumulto, e escreve-se na pedra". Apesar de tantas leis e de tantas lutas, a paz genuína, almejada e merecida, parece algo distante da realidade da Comunidade Kalunga. O tumulto barulhento da desordem, do desprezo do Estado e da lógica fundiária capitalista reinam soberanos no lugar que um dia abrigou pessoas que fugiam tanto do Estado e de suas leis, quanto da lógica précapitalista que lhes impedia de serem livres.

\section{REPRODUÇÃO SOCIAL, DIREITO E VIOLÊNCIA SIMBÓLICA: CONFLITOS INTERNOS NA COMUNIDADE KALUNGA}

Os conflitos territoriais na Comunidade Quilombola Kalunga podem ser analisados sob a lente bourdieusiana, considerando-se a dominação dos grupos econômicos hegemônicos, pela violência simbólica do Estado e pelos mecanismos de reprodução da estrutura das relações de força e das relações simbólicas entre as classes.

Na obra o Poder Simbólico (1989), Bourdieu propõe estudar a ciência jurídica como campo específico, analisando a postura dessa "ciência" a partir dos meandros de seus mecanismos de dominação atuantes na estrutura social de forma visível ou invisível, consciente ou inconsciente. Para o pensador, o poder simbólico revela-se por mecanismos brandos, sutis, de dominação que possuem o mesmo efeito de imposição/dominação que a força física ou o poder econômico.

A reflexão sobre a mudança da lógica endógena da relação quilombola com seus territórios revela o atuar do poder simbólico, exercido pelo Estado e pelos grupos econômicos hegemônicos, sobretudo quando usam o sistema jurídico para domar, 


\section{Daniel Gonçalves de OLIVEIRA Maria Cristina Vidotte Blanco TÁRREGA}

dominar, enquadrar, subverter, homogeneizar o modelo territorial das comunidades tradicionais, gerando (no caso da Comunidade Quilombola Kalunga) tensões internas que rumam para a destruição do modo de vida que lhes são próprios, sobretudo da utilização coletiva do território.

A manutenção da ordem social necessita de um conjunto de ações e mecanismos sociais calibrados para assegurar a reprodução social tal como está. Segundo Pierre Bourdieu (1974), a reprodução social ocorre a partir da reprodução cultural. Na dominação existente no espectro social operam os mecanismos de reprodução da estrutura das relações de força e das relações simbólicas entre as classes. Para o autor a reprodução social deve ser pensada a partir das relações entre poder material e simbólico, que uma vez incorporadas no inconsciente coletivo de percepção, apreciação e ação ajudam a manter estática a ordem social e garantem o perpetuar dos grupos dominantes na posição que ocupam, pondo a salvo as ideologias que eles sustentam.

A reprodução social não se dá tão-somente pela detenção de capital econômico, mas também pela posse de capital cultural, sendo essa última a principal estratégia de reprodução nas sociedades ditas "desenvolvidas". O capital cultural, na compreensão de Bourdieu (em diversas obras), pode ser sintetizado como a incorporação intransferível de capacidades cognitivas sobre os bens e certificados, que possibilita vantagens aos que o detêm. Esse capital é tido como inato, sendo tecido fio-a-fio em um longo processo. Tem por objetivo legitimar os privilégios sociais herdados, garantindo, assim, a manutenção da ordem social, que, para se realizar, precisa acirrar os modos de dominação.

A organização da sociedade esforça-se para manter inabalável a relação entre dominantes e dominados, sendo que os últimos consentem com a ordem social estabelecida de modo pré-reflexivo, tendo-a como a ordem "natural" das coisas e das relações. Esse processo de naturalização da ordem social objetiva de inculcar na compreensão dos sujeitos que essas (re)produções são corretas e que não devem ou não podem ser modificadas porque sempre se deram da forma como estão, e, dessa forma, “enfeitiçam" os sujeitos; nesse contexto, os processos de produção de diferenças (ou de indiferenças) ou de reprodução dessas são percebidos como dados, maquiando, assim, a arbitrariedade da lógica social que institui esses processos de dominação, de manutenção das desigualdades (BOURDIEU, 1974).

Desde a apreensão de sentido referente à reprodução social, insere-se a ideia do direito como instrumento de dominação ou reflexo imediato das tensões existentes, 
Terra versus território: pensar conflitos sobre territorialidades quilombolas a partir da realidade Kalunga

"[...] em que se exprimem as relações econômicas e, em particular, os interesses dos dominantes...” (BOURDIEU, 1988, p. 210). Isso se dá de maneira diferente do que pretende o tradicional debate acerca do direito, dividido entre ideias do formalismo e do instrumentalismo. Os formalistas afirmam "[...] a autonomia absoluta da forma jurídica em relação ao mundo social" (BOURDIEU, 1988, p. 209) e os instrumentalistas concebem "[...] o direito como um reflexo ou um utensílio ao serviço dos dominantes" (BOURDIEU, 1988, p. 209). A vertente instrumentalista encontra eco nos funcionalistas em geral. (CASTANHEIRA NEVES, 1998)

Dessa forma, o Direito não busca a priori a pacificação social de forma equânime, mas se revela muito mais como um instrumento de dominação útil a manter a ordem social das desigualdades, possibilitando a manutenção da dominação e legitimando-a de forma "natural" para os dominados, esforçando-se para se estabelecer na ordem social completamente independente dos constrangimentos e das pressões sociais, tendo por si mesmo como fundamento.

Para Bourdieu o direito é a forma por excelência da violência legítima do Estado. Os discursos e as práticas jurídicas são produtos do funcionamento de um campo direcionado por duas ordens lógicas, de um lado as “[...] relações de força específicas que lhe conferem a sua estrutura e que orientam as lutas de concorrência ou, mais precisamente, os conflitos de competência que nele têm lugar...”. (BOURDIEU, 1988, p. 211). De outro lado, a outra ordem lógica está contida “[...] nas obras jurídicas que delimitam em cada momento o espaço dos possíveis e, deste modo, o universo das soluções propriamente jurídicas.” (BOURDIEU, 1988, p. 211)

Por sua vez, a violência simbólica embutida no processo de manutenção de reprodução social e reafirmada no campo do direito é violência consentida que evidencia a relação de controle não percebida pelos sujeitos, mas que guia a relação sujeito/estrutura, estrutura/sujeito na perspectiva da reprodução social. (BOURDIEU, 2012, p. 239 e 1996, p. 16)

Inserindo-se a análise do caso dos conflitos territoriais kalungas nesse contexto, tem-se que a incongruência gerada pela oposição entre as manifestações de interesse de titulação individual ou coletiva acaba por desencadear processos de violência física e simbólica na Comunidade. Processos esses resultantes da inserção dos sujeitos na dinâmica da ideologia capitalista que pressupõe a mercantilização da terra com a consequente pretensão da propriedade individual sobre uma porção do território coletivo. Dessa lógica subversiva de propriedade capitalista imposta aos kalungas pelos 


\section{Daniel Gonçalves de OLIVEIRA Maria Cristina Vidotte Blanco TÁRREGA}

mecanismos de dominação do poder simbólico, decorre uma série de consequências externas que os levam a considerar a titulação individual como a melhor forma de garantia de seus direitos. Um exemplo disso é a facilidade do acesso ao crédito para os proprietários individuais pelo fornecimento da garantia de bem imóvel alienável. Para os detentores de títulos individuais conferidos pelo IDAGO, lhes é garantido o acesso ao crédito rural, uma vez que a terra pode ser dada em garantia, e os sucessores do primeiro titular poderão alienar (se assim quiserem) seu quinhão no território.

No caso Kalunga, os instrumentos simbólicos da dominação, o discurso jurídico da propriedade, a prática jurídica das garantias creditícias, entre outras tantas, calibram a produção social e sufocam a cultura local, fazendo incompreensível na realidade (im)posta a forma ancestral de uso coletivo da terra. A imposição aos atores sociais do modelo hegemônico da posse, propriedade e titulação individual e o complexo de teorias, teses e princípios da dogmática jurídica, somadas à violência, física e simbólica, consentida ao Estado, poderá causar no futuro à Comunidade Kalunga o risco de desestruturação e extinção do território.

O conceito ancestral de territorialidade dá outra dimensão da ocupação da terra, muito mais ampla do que os institutos jurídicos da detenção, da posse, ou do domínio. Significa a ocupação nas experiências material, espiritual, coletiva, atemporal. Experiência que pode se manifestar nos tempos diversos - presente, no passado e no futuro. (TARREGA, 2016)

Num contraponto a hegemonia do direito moderno que guia o ordenamento brasileiro, a Convenção 169 da OIT, que foi ratificada pelo Estado brasileiro, garante aos povos tribais - como os kalungas - autonomia para deliberarem conforme seus usos e costumes sobre causas complexas como a utilização e titulação de seu território. Todavia, resistir às violências simbólicas e aos instrumentos de dominação é muito difícil. Assim, persiste a dúvida sobre qual será a lógica de utilização do território e em um futuro próximo qual a realidade cultural que restará das imposições sociais a nortear a discussão e a decisão dos kalungas para suas questões territoriais. Lembrando que identidade e territorialidade não se sobrepõem, mas funcionam como causa e efeito um do outro, numa situação paradoxal como afirma Ost. (TARREGA; RODRIGUES, 2013, p.44)

Daniel Sandoval (2016) explica hegemonia como a direção política de uma sociedade mediante um consenso na aceitação de sua dominação. Esse consenso pode ser construído através de um uso ideologizado da linguagem e não como um acordo consciente entre todos os membros da comunidade. 
Terra versus território: pensar conflitos sobre territorialidades quilombolas a partir da realidade Kalunga

O temor de esfacelamento da comunidade e extinção de um modo tradicional de vida é real e iminente, em razão das disparidades originárias dos discursos e práticas jurídicas que deram causa e mantêm os conflitos internos orientados por uma ou outra lógica quanto ao território na Comunidade Kalunga.

Nesse sentido, escrever direitos não significa efetivá-los, não ao menos como dever ser; logo, a fórmula "direito a ter direitos" esvazia-se, à medida que esses direitos não garantem os bens necessários e/ou não dão condições materiais para serem cobrados e/ou existirem na prática (HERRERA FLORES, 2009).

Esta é a realidade dos territórios quilombolas - a inserção deste direito na Constituição e posterior edição de um decreto regulamentador em 2003, não garantem a necessária proteção ou regularização de forma consistente. Ao contrário disso, desloca o eixo dos conflitos, inserindo-os internamente, produzindo processos sociais de violência simbólica a partir da disputa dentro da comunidade das formas de ver e de pensar o território. Esse processo se instaura “[...] com a cumplicidade tácita daqueles que a sofrem e, também, frequentemente, daqueles que a exercem na medida em que uns e outros são inconscientes de a exercer ou a sofrer" (BOURDIEU, 1996, p. 16). Logo, é possível compreender que a violência simbólica impregnada nos conflitos internos da Comunidade Kalunga são "[...] formas de coerção que se baseiam em acordos não conscientes entre as estruturas objetivas e as estruturas mentais" (BOURDIEU, 2012, p. 239), sendo que nessa vereda, tais processos de violência simbólica (inconscientes e quase sempre imperceptíveis pelos sujeitos da Comunidade Kalunga) são criados e regidos pelo Estado, uma vez que “[...] O Estado é o que funda a integração lógica e a integração moral do mundo social e, por aí, o consenso fundamental sobre o sentido do mundo que é a condição mesma dos conflitos a propósito do mundo social” (BOURDIEU, 2012, p. 15).

Nesse compasso, cabe ressaltar que a terra, enquanto espaço habitável e base física de reprodução e manutenção dos meios e modos de vida da Comunidade Kalunga, foi traduzida para o direito pelo capital, dentro deste sistema hegemônico que visa a assegurar o acúmulo de riquezas, propiciando a manutenção da estrutura agrária colonial, baseada na propriedade privada, num claro intuito de desprezar e expulsar aqueles que "vivem na terra e da terra".

Esse desprezo pela propriedade tradicional é mostrado por Zibetti (2005) que analisa a marginalização dos povos e comunidades tradicionais no acesso e permanência à terra, lembrando que as propriedades coletivas e comunais eram consideradas como bens de mãos mortas o que tinha por consequência a expropriação ou confisco desse tipo 


\section{Daniel Gonçalves de OLIVEIRA Maria Cristina Vidotte Blanco TÁRREGA}

de propriedade, e por outro lado permitia a maior concentração latifundista da propriedade agrária.

Esse descaso do direito moderno com os modos de permanência tradicionais e a supervalorização mercadológica da terra como bem imóvel geram conflitos ideológicos entre os partícipes das comunidades, diferentes atores sociais. Tem-se que os conflitos internos na Comunidade Kalunga fincam "[...] sua raiz [...] no processo de transformação da terra em equivalente de mercadoria [...]. A mercantilização subjuga e tende a diluir outros significados dados à terra pelos que nela vivem" (MEDEIROS, 2014, p. 26).

Isso se reforça pela necessidade capitalista da desocupação da terra e do rompimento de qualquer vínculo cultural do homem com o espaço que ocupa. A ideologia proprietária moderna e capitalista entende a terra como mercadoria e para que seja uma efetiva mercadoria deve estar vazia. Tudo o que torna a terra permanentemente ocupada, como a natureza animal e vegetal, os índios e as populações tradicionais e seus vínculos culturais são obstáculos para o exercício do direito de propriedade e considerado entrave ao livre desenvolvimento capitalista. (SOUZA FILHO, 2015, p. 57).

Carlos Frederico Marés de Souza Filho, em sua obra A Função Social da Terra (2003), assegura que a transformação da terra em propriedade privada absoluta e individual é recente. É uma criação da civilização europeia, recente na história e difundido pelo colonialismo ao resto do mundo. Em razão do surgimento da propriedade privada, os anseios de liberdade "tanto dos trabalhadores como dos Povos da América Latina" foram frustrados. Ao ressaltar a função social da terra, contrapondo-se à função da propriedade privada afirma a possibilidade da preservação da terra coletiva "[...] nos sistemas jurídicos capitalistas nos quais os direitos coletivos se sobrepõem aos individuais, como o brasileiro" (MARÉS, 2003). Afirma, outrossim, que usar adequadamente a terra e mantendo-a "[...] como área de proteção são imperativos coletivos, protegem a biodiversidade e a sociodiversidade" (MARÉS, 2003).

Nesse compasso, Regina Bruno na obra Senhores da terra, senhores da guerra: a nova face política das elites agroindústrias no Brasil (1997), afirma que a estrutura agrária latifundiária de hoje mantém uma íntima ligação com o capital financeiroindustrial nacional e internacional e nunca deixou de reproduzir-se de forma improdutiva e violenta de modo a legitimar mitos e ideologias das velhas e novas classes e grupos dominantes.

Alfredo Wagner Berno de Almeida no artigo Terras Tradicionalmente R. Fac. Dir. UFG, v. 41, n.2, p.219-236, maio / ago. 2017 
Terra versus território: pensar conflitos sobre territorialidades quilombolas a partir da realidade Kalunga

Ocupadas (2004), assevera que as políticas ambientais e agrárias ressentem-se quanto à instrumentalização de suas competências, faltando-lhes recursos técnicos "[...] que lhes possam permitir uma compreensão mais precisa das modalidades de uso comum vigentes" (ALMEIDA, 2004) e necessários aos povos e grupos que clamam pelo reconhecimento de suas identidades coletivas e do espaço territorial que reivindicam.

Observa-se, segundo os argumentos dos autores em referência que o modelo de propriedade privada é uma imposição da ideologia capitalista devidamente instrumentalizada pelo direito brasileiro contemporâneo. Entretanto, esse mesmo ordenamento, cedendo a tensões internas criou mecanismos de empoderamento das coletividades, que podem ser a opção de resistência na eleição do seu modelo de exploração econômica do território.

\section{CONSIDERAÇÕES FINAIS}

O silêncio sobre o direito dos afrodescendentes desde o fim do regime escravagista até a Constituição de 1988 encobriu também as questões territoriais dos quilombolas, a invisibilidade política e social. Esse hiato produziu discursos e práticas jurídicas incompatíveis com os vínculos identitários dos sujeitos com seu território. Fomentou a dominação cultural provocada pela ideologia capitalista presente nos documentos formais conferidos e ou reconhecidos pela ordem estatal posta, pela contradição deles com as formas de ser e viver dentro desse espaço social, gerando tensões e conflitos internos que perduram mesmo depois da inclusão do reconhecimento das territorialidades política e juridicamente no Brasil.

A resistência e a luta quilombola por visibilidade e acesso a uma política pública de regularização fundiária eficaz, que contemplasse as especificidades da compreensão da "territorialidade" e do "território" numa perspectiva existencial, não foram satisfeitas com a previsão do art. 68 do ADCT. O fim do regime escravagista deuse sem a devida reparação econômica e sem a redistribuição de terras aos sujeitos vitimados e esse contexto não se modificou com a redemocratização do país em 1988. A Carta Constitucional não resolveu o problema no sentido material e o fez de modo incompleto ou desconexo da realidade no sentido formal, pois, ao omitir textualmente, no art. 68 da ADCT, as peculiaridades do território quilombola, acabou por propiciar formas aberrantes de realização da política de regularização fundiária nas diversas comunidades, em todo o território nacional. 


\section{Daniel Gonçalves de OLIVEIRA Maria Cristina Vidotte Blanco TÁRREGA}

O modelo de direito e de estado brasileiro, seus instrumentos e a execução da regularização fundiária nos territórios quilombolas, especificamente, na Comunidade Kalunga, instaurou tensões sociais internas, a partir da subversão da lógica utilitária coletiva do território, mediante a concessão de títulos individuais, dividindo e reduzindoo à propriedade individual, a bem imobiliário, a terra mercadoria, terra vazia.

Os conflitos internos gerados pelas contradições jurídicas e a incompreensão da territorialidade específica dos quilombolas carecem de respaldo do direito agrário tradicional. Da mesma forma escapam a esse campo jurídico os direitos coletivos da Comunidade Quilombola Kalunga, incluindo aqueles que lhes asseguram viver conforme seus usos e costumes tradicionais no território que historicamente ocupam e para o qual atribuem significados não expressos nos textos jurídicos. É preciso dar amplitude à compreensão jurídica, pautada hoje sobremaneira por valores meramente econômicos, presentes na ideologia capitalista que, inserta no direito, o transforma em mero instrumento de dominação, servindo-se para isso da dominação do patrimônio cultural.

O direito agrário deve se converter em direito revolucionário, humanitário e orientado para a paz, como bem exorta Ricardo Zeledón (1999), seus pressupostos teóricos devem se construir a partir da ótica dos sujeitos e da jusdiversidade, permitindo a manutenção do modo comunal, solidário e cooperativo de viver nos territórios ancestrais para realizar a função social da terra e a prevalência dos direitos coletivos como quer Carlos Frederico Marés.

\section{REFERÊNCIAS BIBLIOGRÁFICAS}

ALMEIDA, Alfredo Wagner Berno de. Terra de quilombo, terras indígenas, "babaçuais livres", "castanhais do povo", faxinais e fundos de pasto: terras tradicionalmente ocupadas. Manaus: PGSCA-UFAM, 2008.

Terras Tradicionalmente Ocupadas. Revista Brasileira de Estudos Urbanos e Regionais, v.6, n.1, p. 09-31, maio de 2004.

ALMEIDA, Maria Geralda de. O território e a comunidade Kalunga: Quilombolas em diversos olhares/ Maria Geralda de Almeida. Goiânia: Universidade Federal de Goiás, 2015.

ARRUTI, José Maurício. Propriedade ou território? Tempo e Presença, São Paulo; Rio de Janeiro, v. 21, n. 307, set-out. 1999.

BAIOCHHI, Mari de Nasaré. Kalunga - A sagrada terra. Revista da Faculdade de Direito da UFG, v. 19-20, n.1, p.107-120, jan-dez, 1995-1996. 
Terra versus território: pensar conflitos sobre territorialidades quilombolas a partir da realidade Kalunga

Kalunga Povo da Terra. 3. ed. Goiânia: Editora UFG, 2013.

BOURDIEU, Pierre. O Poder Simbólico. Rio de Janeiro, Lisboa: Difel e Bertrand Brasil, 1989.

. A Miséria do Mundo. Petrópolis, RJ: Vozes, 1997.

O Desencantamento do Mundo. São Paulo: Perspectiva, 1979.

Papirus, 1996.

Sur la télévision. Paris: Liber, 1996.

Reprodução social e reprodução cultural. In: BOURDIEU, P. A economia das trocas simbólicas. São Paulo: Perspectiva, 1974, p. 295-336. d'Agir/Seuil, 2012.

BRUNO, Regina. Senhores da terra, Senhores da guerra: a nova face política das elites agroindustriais no Brasil. Rio de Janeiro: Forense Universitária; UFRJ, 1997.

CASTANHEIRA NEVES, Antônio. Entre o Legislador, a Sociedade e o Juiz ou entre Sistema, Função e Problema - Os modelos actualmente alternativos da realização juridiscional do Direito. Boletim da Faculdade de Direito, Coimbra, Volume LXXIV, p. 1-44, 1998.

FRANCO, Rangel Donizete. Desapropriação: limites e possibilidades na regularização dos territórios Quilombolas. Curitiba: Juruá, 2014.

FUNDAÇÃO CULTURAL PALMARES. Disponível em: $<$ http://www.palmares.gov.br/wp-content/uploads/2017/05/quadro-geral-15-05-

2017.pdf.> Acesso em: 24 jun. 2017.

GOMES, Lilian Cristina Bernardo. O Direito Quilombola e os Entraves da Estrutura Agrária Fundiária Brasileira. In: TARREGA, Maria Cristina Vidotte Blanco; SCHWENDLER, Sonia Fatima (Org.). Conflitos agrários. Seus Sujeitos, seus direitos. 1. ed. Goiânia: Editora da PUC Goiás, 2015, p. 239-269.

HERRERA FLORES, Joaquín. A (re)invenção dos direitos humanos. Trad. Carlos Roberto Diogo Garcia, Antônio Henrique Graciano Suxberger e Jefferson Aparecido Dias. Florianópolis: Fundação Boiteux, 2009.

INSTITUTO NACIONAL DE COLONIZAÇÃO E REFORMA AGRÁRIA. Disponível em: 〈http://www.incra.gov.br/quilombola>. Acesso em: 24 jun. 2017.

LITTLE, Paul. Territórios Sociais e Povos Tradicionais no Brasil: por uma antropologia da territorialidade. Brasília: Universidade de Brasília, Série Antropologia $\mathrm{n}^{\mathrm{o}}$ $322,2002$. 
MEDEIROS, Leonilde Servolo de. Conflitos Fundiários e Violência no Campo. Conflitos no Campo Brasil, v. 30, p. 26-30, 2015.

POLANYI, K. A Grande Transformação: as origens da nossa época. 9. ed. Rio de Janeiro: Editora Campus, 2000.

RIBEIRO, Darcy. O Povo Brasileiro: A formação e o sentido do Brasil. São Paulo: Companhia das Letras, 1995.

SANDOVAL, Daniel. Historia Crítica Del Derecho Y Crítica Jurídica. In: Revista da Faculdade de Direito da UFG, v. 40, n.1, p. 13 - 30, jan. / jun. 2016.

SANTOS, MILTON. A natureza do espaço. São Paulo: Hucitec, 1996.

SOUZA FILHO, Carlos Frederico Marés. A Função Social da Terra. Porto Alegre: Sérgio Antônio Fabris Editor, 2003.

; TÁRREGA, Maria Cristina Vidotte Blanco; WOLKMER, Antônio Carlos (org.). Os Direitos Territoriais Quilombolas - Além do Marco Temporal. Goiânia, Editora PUC Goiás, 2016.

TARREGA, Maria Cristina V. B.; RODRIGUES, Barbara Luiza R. Sobre Afetividade e Des-Envolvimento: Comunidades Remanescentes de Quilombos e Território In: II Congresso Internacional de Direito Agrário: Sujeitos da/na América Latina comunidades tradicionais e natureza, 2013, Florianópolis. Anais do II Congresso Internacional de Direito Agrário, 2013. v. 1. p. 40-45.

TARREGA, Maria Cristina V.B. e SCHWENDLER, Sonia. Conflitos Agrários. Seus sujeitos seus direitos. Goiânia. Editora PUC Goiás, 2015.

ZELEDON, Ricardo Zeledon. EL DERECHO AGRARIO COMO DERECHO PARA LA PAZ. In: Revista de la Facultad de Derecho, n. 16, p. 136 - 168, julio-diciembre 1999.

ZIBETTI, Darcy Walmor. Teoria tridimensional da função da terra no espaço rural, econômica, social e ecológica. São Paulo: Ed. Juruá, 2005.

Artigo recebido 28 de junho de 2017 e aceito em 25 de novembro de 2017 